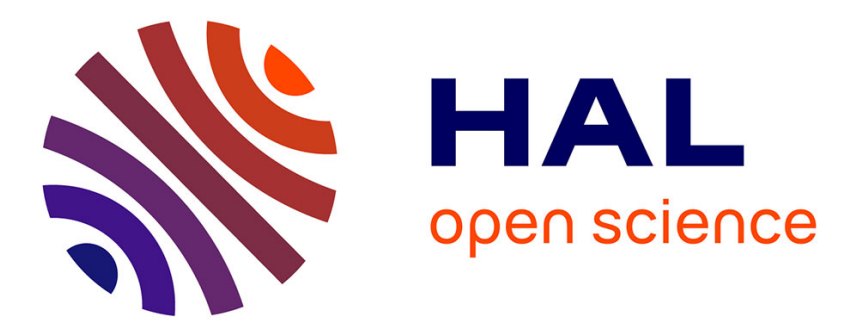

\title{
Divergent regulation of the key enzymes of polyamine metabolism by chiral $\alpha$-methylated polyamine analogs
}

Mervi T Hyvönen, Michael T Howard, Christine B Anderson, Nikolay

Grigorenko, Alex R Khomutov, Jouko Vepsäläinen, Leena Alhonen, Juhani

Jänne, Tuomo A Keinänen

\section{To cite this version:}

Mervi T Hyvönen, Michael T Howard, Christine B Anderson, Nikolay Grigorenko, Alex R Khomutov, et al.. Divergent regulation of the key enzymes of polyamine metabolism by chiral $\alpha$-methylated polyamine analogs. Biochemical Journal, 2009, 422 (2), pp.321-328. 10.1042/BJ20090737. hal00479194

\section{HAL Id: hal-00479194 \\ https://hal.science/hal-00479194}

Submitted on 30 Apr 2010

HAL is a multi-disciplinary open access archive for the deposit and dissemination of scientific research documents, whether they are published or not. The documents may come from teaching and research institutions in France or abroad, or from public or private research centers.
L'archive ouverte pluridisciplinaire HAL, est destinée au dépôt et à la diffusion de documents scientifiques de niveau recherche, publiés ou non, émanant des établissements d'enseignement et de recherche français ou étrangers, des laboratoires publics ou privés. 
Divergent Regulation of the Key Enzymes of Polyamine Metabolism by Chiral $\alpha$-methylated polyamine analogs

Mervi T. Hyvönen ${ }^{* 1}$, Michael T. Howard ${ }^{\ddagger}$, Christine B. Anderson ${ }^{\ddagger}$, Nikolay Grigorenko ${ }^{\S}$, Alex R. Khomutov ${ }^{\S}$, Jouko Vepsäläinen ${ }^{\dagger}$, Leena Alhonen*, Juhani Jänne*, Tuomo A. Keinänen*

*Department of Biotechnology and Molecular Medicine, A. I. Virtanen Institute for Molecular Sciences, and ${ }^{\dagger}$ Laboratory of Chemistry, Department of Biosciences, Biocenter Kuopio, University of Kuopio, Kuopio, Finland; ${ }^{\dagger}$ Human genetics, University of Utah, Salt Lake City, USA; ${ }^{\S}$ Engelhardt Institute of Molecular Biology, Russian Academy of Sciences, Moscow, Russia

${ }^{1}$ To whom correspondence should be addressed: Dr. Mervi T. Hyvönen, A.I.Virtanen Institute for Molecular Sciences, University of Kuopio, P.O.Box 1627, 70211 Kuopio, Finland. Street address: Yliopistonranta 1E, 70210 Kuopio, Finland. Tel: +358443552092. Fax: +35817163025. Email: mervi.hyvonen@uku.fi

Running title: Chiral $\alpha$-methylated polyamine analogs

The natural polyamines are ubiquitous multifunctional organic cations which play important roles in regulating cellular proliferation and survival. Here we present a novel approach to investigate polyamine functions by using optical isomers of $\alpha$-methylspermidine (MeSpd) and $\alpha, \omega$ bismethylspermine $\left(\mathrm{Me}_{2} \mathrm{Spm}\right)$, metabolically stable functional mimetics of natural polyamines. We studied the ability of $\alpha-\mathrm{MeSpd}$ and $\alpha, \omega-\mathrm{Me}_{2} \mathrm{Spm}$ to alter the normal polyamine regulation pathways at the level of polyamine uptake and the major control mechanisms known to affect the key polyamine metabolic enzymes. These include: 1) ornithine decarboxylase (ODC), which catalyzes the rate limiting step of polyamine synthesis, 2) ODC antizyme, an inhibitor of ODC and polyamine uptake, 3) spermidine/spermine $\mathbf{N}^{1}$-acetyltransferase (SSAT), the major polyamine catabolic enzyme, and 4) S-adenosyl-L-methionine decarboxylase (AdoMetDC) which is required for the conversion of putrescine to spermidine and spermidine to spermine. We show that the stereoisomers differ in their cellular uptake, and ability to downregulate ODC and AdoMetDC, and to induce SSAT. These effects are mediated by the ability of the enantiomers to induce +1 ribosomal frameshifting on ODC antizyme mRNA, to suppress the translation of AdoMetDC uORF and to regulate the alternative splicing of SSAT pre-mRNA. The unique effects of chiral polyamine analogs on polyamine metabolism may offer novel possibilities for studying the physiological functions, control mechanisms, and targets of the natural polyamines, as well as advance therapeutic drug development in cancer and other human health related issues.

Keywords: polyamines, optical isomers, frameshifting, upstream open reading frame, alternative splicing, difluoromethylornithine

Abbreviations: AdoMetDC, S-adenosyl-L-methionine decarboxylase; AZ, antizyme; CHX, cycloheximide, DENSPM, $N^{1} N^{11}$-diethylnorspermine; deSAM; decarboxylated S-adenosyl-L-methionine; DFMO, difluoromethylornithine; eIF5A, eukaryotic translation initiation factor 5A; MeSpd, $\alpha$ methylspermidine; $\mathrm{Me}_{2} \mathrm{Spm}, \alpha, \omega$-bismethylspermine; NMD, nonsense-mediated mRNA decay; ODC, ornithine decarboxylase; PAO, polyamine oxidase; $\mathrm{Pu}$; putrescine; SAM, S-adenosyl-L-methionine; SMO, spermine oxidase; Spd, spermidine; Spm, spermine; SSAT, spermidine/spermine $\mathrm{N}^{1}$ acetyltransferase; uORF, upstream open reading frame.

\section{INTRODUCTION}


Polyamines are achiral organic polycationic compounds that play a critical role as regulators of important cellular processes such as proliferation, differentiation and modulation of ion channels [1]. As expected for a molecule with multiple cellular roles, polyamine levels are tightly controlled through a series of feedback circuits to maintain appropriate intracellular concentrations. The key regulatory enzymes in the polyamine biosynthesis are ornithine decarboxylase (ODC) and S-adenosyl-L-methionine decarboxylase (AdoMetDC). During catabolism of polyamines, spermidine/spermine $\mathrm{N}^{1}$-acetyltransferase (SSAT) is the rate-controlling enzyme of polyamine oxidase (PAO)-mediated back-conversion of spermine and spermidine to spermidine and putrescine, respectively. Based on the observations that increased polyamine levels are correlated with, and can promote neoplastic growth, it has been proposed that reducing or depleting intracellular polyamines is an appropriate therapy for cancer and other diseases involving undesired cellular proliferation. Towards this end, inhibitors of the ODC and AdoMetDC [2-4] have been identified and polyamine analogues have been designed with the intent of affecting multiple targets in the polyamine pathway. Several of these compounds alone or in combination are currently in clinical trials [5-8] as potential anti-cancer agents.

Due to their positive charge at physiological $\mathrm{pH}$, a major fraction of polyamines is electrostatically bound to anionic cellular sites such as RNA, DNA and phospholipids. Thus, polyamines are involved in regulation of many levels of gene expression, by influencing chromatin condensation, DNA stability and structure, RNA processing and translation. One very specific target of polyamine-mediated regulation is the programmed frameshifting of eukaryotic ODC antizyme [9, 10] and TY1 transposon [11]. Antizyme is a small regulatory protein which binds to and inhibits ODC and targets it to the proteasome for degradation. In addition, antizyme negatively regulates the polyamine uptake system [12, 13]. The synthesis of antizyme is controlled by cellular polyamine concentration at the level of translation, whereby polyamines greatly increase the efficiency of +1 ribosomal frameshifting, allowing the production of functional, full-length protein, thus completing an autoregulatory circuit controlling polyamine synthesis and transport.

The feedback regulation of AdoMetDC by spermidine and spermine involves control of translational initiation. The AdoMetDC 5' leader sequence harbours an upstream open reading frame (uORF), which codes for a small regulatory peptide with the sequence MAGDIS [14]. When polyamine levels are low ribosomes pause after $\mathrm{uORF}$ termination but are able to continue to AdoMetDC reading frame. By contrast, elevated polyamine levels stabilize the ribosomal pause in the vicinity of uORF termination codon, and inhibit the completion of UORF peptide synthesis reducing translation of the AdoMetDC ORF.

We recently discovered a novel regulation mechanism for the expression of SSAT, where polyamines modulate the alternative splicing of SSAT pre-mRNA [15]. Low polyamine levels result in accumulation of an unproductive splice variant (SSAT-X), which is rapidly degraded by the protein synthesisdependent mRNA surveillance pathway known as nonsense-mediated mRNA decay (NMD). By contrast, high polyamine levels favour generation of the productive mRNA variant (SSAT), resulting in synthesis of active SSAT enzyme protein, leading to decreased polyamine levels.

Although complex feedback mechanisms have been found for all key metabolic enzymes controlling cellular polyamine levels, the underlying regulatory mechanisms of these specific processes are not yet understood. Thus, new specific tools are needed to manipulate the polyamine metabolism. $\alpha$-Methylated polyamine analogs are functional mimetics for natural polyamines both in vivo and in vitro [16-18]. $\alpha$ methylated spermidine (MeSpd) and spermine $\left(\mathrm{Me}_{2} \mathrm{Spm}\right)$ are not cytotoxic and fulfil many cellular functions of the natural polyamines and support proliferation. Because they are metabolically much more stable than their natural counterparts and replace the natural polyamines by enhancing polyamine efflux and inhibiting uptake, the $\alpha$-methylated analogs are convenient tools for polyamine research. Unlike the natural polyamines, the $\alpha$-methylated analogs are chiral. Since chirality plays an important role in nature by controlling the binding and metabolic transformation of the compounds in living systems, we rationalized that the stereoisomers of $\alpha$-methylated polyamine analogs may possess divergent biological properties. Indeed, the investigation of these novel chiral analogs led to the discovery of the hidden 
stereospecificity of several enzymes of polyamine metabolism, such as polyamine oxidase (PAO) [19], spermine oxidase (SMO) and deoxyhypusine synthase [20].

Here we investigated the differences between the stereoisomers of $\mathrm{MeSpd}$ and $\mathrm{Me}_{2} \mathrm{Spm}$ in their cellular uptake and their ability to regulate the key enzymes of polyamine metabolism. Our results revealed significant differences between the stereoisomers on the major known polyamine feedback regulatory mechanisms which control intracellular polyamine levels.

\section{EXPERIMENTAL Materials}

Human epithelial kidney cell line (HEK293) and human prostate carcinoma cell line (DU145) were obtained from American Type Culture Collection. Nontransgenic mouse primary foetal fibroblasts were prepared as previously published [21]. The optical isomers of $\alpha$-methylspermidine (MeSpd) and $\alpha, \omega$ bismethylspermine $\left(\mathrm{Me}_{2} \mathrm{Spm}\right)$ were synthesized as described in [22]. Difluoromethylornithine (DFMO) was obtained from ILEX oncology Inc. $\left[{ }^{14} \mathrm{C}\right]$-labelled spermine tetrahydrochloride (specific activity 112 $\mathrm{mCi} / \mathrm{mmol}$ ), spermidine trihydrochloride (specific activity $113 \mathrm{mCi} / \mathrm{mmol}$ ) and carboxyl-S-adenosyl-Lmethionine (specific activity $54 \mathrm{mCi} / \mathrm{mmol}$ ) were from GE Healthcare.

\section{Cell culture}

HEK 293 cells were cultured in DMEM, $10 \% \mathrm{FBS}$ at $+37^{\circ} \mathrm{C}$ and $5 \% \mathrm{CO}_{2}$. Primary fetal fibroblasts and DU145 cells were cultured in Dulbecco's Modified Eagle's Medium (DMEM, Sigma) supplemented with $10 \%$ heat-inactivated FBS (Gibco) and $50 \mu \mathrm{g} / \mathrm{ml}$ gentamycin (Gibco), and incubated in humidified atmosphere $+37{ }^{\circ} \mathrm{C}, 10 \% \mathrm{CO}_{2}$. When natural polyamines were used, $1 \mathrm{mM}$ aminoguanidine was included to prevent the oxidation of Spd and Spm by serum amine oxidases. Analog concentration of $100 \mu \mathrm{M}$ was used to effectively replace the natural polyamines with the analogs. The cells were harvested by trypsinization, washed with PBS, pelleted and stored in $-70{ }^{\circ} \mathrm{C}$. The cell number was measured electronically with Coulter Counter model Z1. Cell pellets were lysed in buffer ( $20 \mathrm{mM}$ Tris-HCl pH 7.4, $1 \mathrm{mM}$ EDTA, $0.1 \%$ Triton X-100, $1 \mathrm{mM}$ dithiothreitol, Complete EDTA-free (Roche)) and incubated for $20 \mathrm{~min}$ on ice. For AdoMetDC activity assay, the cell samples were lysed in buffer containing $50 \mathrm{mM}$ potassium phosphate buffer $\mathrm{pH} 7.2,0.1 \mathrm{mM}$ EDTA, $0.1 \%$ Triton X-100 and $1 \mathrm{mM}$ dithiothreitol. Samples for polyamine measurement were taken and the rest of the lysate was centrifuged for $12000 \mathrm{xg}$ $20 \mathrm{~min}+4{ }^{\circ} \mathrm{C}$. The supernatant fraction was used for enzymatic assays of SSAT, ODC and AdoMetDC. Total protein concentration was measured using Coomassie Brilliant Blue (Bio Rad) with dilutions of bovine serum albumin (Sigma) as standards.

\section{Enzyme activities and polyamines}

Intracellular polyamines, polyamine analogs and nucleosides were measured with HPLC according to the published method [23]. The amount of DNA was measured from pellets of polyamine samples according to the method of Giles and Myers [24]. ODC and SSAT activities were measured as described earlier [25, 26]. AdoMetDC activity was measured by a similar method as ODC activity, using reaction buffer consisting of $50 \mathrm{mM}$ potassium phosphate buffer $\mathrm{pH} 7.4,1.25 \mathrm{mM}$ dithiothreitol, $3 \mathrm{mM}$ putrescine, 0.2 $\mathrm{mM}$ S-adenosyl-L-methionine and $25 \mu \mathrm{Ci} / \mathrm{ml}\left[{ }^{14} \mathrm{C}\right.$-carboxyl $]-\mathrm{S}$-adenosyl-L-methionine.

\section{Alternative splicing of SSAT}

Primary mouse foetal fibroblasts were plated on 6-well plates and grown overnight. Fresh medium containing $10 \mu \mathrm{g} / \mathrm{ml}$ cycloheximide was changed. After an hour, polyamine analogs $(100 \mu \mathrm{M})$ were added, and the cells were further incubated for $7 \mathrm{~h}$. RNA extraction, DNase-treatment, cDNA synthesis and quantitative RT-PCR were carried out as previously published [15].

\section{Uptake competition experiments}


DU145 cells were plated onto 6-well plates at density of $0.3 \times 10^{6}$ cells/well. After overnight incubation, pre-warmed serum-free medium supplemented with $10 \mu \mathrm{M}\left[{ }^{14} \mathrm{C}\right]-\mathrm{Spd}$ or $\left[{ }^{14} \mathrm{C}\right]-\mathrm{Spm}$ (specific activity 25 $\mathrm{mCi} / \mathrm{mmol})$ and competing polyamine analogs $(1-100 \mu \mathrm{M})$ was changed. After 10-min incubation, the medium was aspirated, the plates washed twice with ice-cold PBS and the cells lysed in $500 \mu 1$ of $0.5 \mathrm{M}$ $\mathrm{NaOH}$. Four hundred $\mu \mathrm{l}$ of the lysate was mixed with $3 \mathrm{ml}$ of Optiphase HiSafe scintillation cocktail (Perkin Elmer) and counted by liquid scintillation counter (1450 Microbeta PLUS, Wallac). Total protein concentration was measured from the lysate using Coomassie Brilliant Blue (Bio-Rad).

\section{Antizyme frameshifting in HEK293 cells and in vitro}

Frameshifting assay was essentially carried out as described in [27, 28]. In brief, HEK293 cells were plated at $7 \times 10^{3}$ cells/well of $1 / 2$-area 96 -well plate. After 48 hours culture in $2.5 \mathrm{mM}$ DFMO the cells were transfected with $50 \mathrm{ng} /$ well p2luc reporter plasmid [29] and $0.2 \mu 1$ of Lipofectamine 2000. Reporter plasmid contains antizyme frameshifting sequences needed for polyamine induction between the Renilla and firefly luciferase genes. The firefly luciferase ORF lacks an initiation codon and can only be expressed as a fusion protein with Renilla luciferase if translational frameshifting occurs. After 12 hours, polyamine analogs, $1 \mathrm{mM}$ aminoguanidine and $2.5 \mathrm{mM}$ DFMO were added. The cells were lysed 24 hours later and Relative Light Units were measured following an autoinjection of the Dual Luciferase Reporter Assay reagents using a Veritas Luminometer (Turner Biosystems). In vitro frameshifting assays were carried out according to manufacturer's specifications using the TNT Quick Coupled Transcription/Translation system (Promega) in a final volume of $10 \mu$ supplemented with varying concentrations of polyamine analogs. After incubating for 1 hour at $30^{\circ} \mathrm{C}$, reactions were diluted 10 -fold in Passive Lysis Buffer supplied with the Dual Luciferase Reporter Assay (Promega) reagents. Frameshifting efficiency was calculated as a ratio of the firefly to Renilla luciferase activities standardized to an in-frame control.

\section{AdoMetDC uORF translation in vitro}

Plasmids containing AdoMetDC uORF-luciferase fusion construct or a similar construct where uORF initiation codon AUG was mutated to AUA, were a kind gift from Dr. David Morris (USA) [30]. The plasmids were produced in E. coli, purified with QIAFilter Maxi Kit (Qiagen) and linearized with EcoRI. Capped mRNAs were synthesized using RiboMAX Large Scale RNA production system (T7) in vitro transcription kit (Promega) and ribo $\mathrm{m}^{7} \mathrm{G}$ cap analog (Promega) according to the manufacturer's instructions. After purification, in vitro translation reactions $(25 \mu \mathrm{l})$ were carried out using Flexi rabbit reticulocyte lysate (Promega) and added polyamine (100 $\mu \mathrm{M} \mathrm{Spm}$ and $\mathrm{Me}_{2} \mathrm{Spm}, 250 \mu \mathrm{M}$ Spd and $\mathrm{MeSpd}$ ). The endogenous spermidine and spermine levels in the lysate were 440 and $40 \mu \mathrm{M}$, respectively. Final $\mathrm{Mg}^{2+}$ and $\mathrm{K}^{+}$concentrations in the reactions were 3.2 and $75 \mathrm{mM}$, respectively. Luminescence was measured as quadruplicates with Victor ${ }^{2}$ Multilabel Counter (Wallac) from $5 \mu$ of the lysate mixed with $100 \mu 1$ of Luciferase assay reagent (Promega).

\section{Statistical analysis}

Values are means \pm S.D. One-way analysis of variance (ANOVA) with Tuckey's post-hoc test was used for multiple comparisons with the aid of a software package, GraphPad Prism 4.03 (GraphPad Software Inc.). ${ }^{*}, * *$ and $* * *$ refer to $p$ values of $<0.05,<0.01$ and $<0.001$, respectively.

\section{RESULTS}

\section{Polyamine concentrations, ODC, AdoMetDC and SSAT activities}

To examine the effect of the stereoisomers of MeSpd and $\mathrm{Me}_{2} \mathrm{Spm}$ on intracellular polyamine concentrations and on the enzyme activities of ODC, SSAT and AdoMetDC, DU145 prostate cancer cells were treated with $100 \mu \mathrm{M}$ of the analogs for 72 hours, with or without $5 \mathrm{mM}$ difluoromethylornithine (DFMO), an irreversible ODC inhibitor. As shown in Tables 1 and 2, S-MeSpd and S,S-Me $\mathrm{Me}_{2} \mathrm{Spm}$ were the most effective stereoisomers to inhibit ODC activity. In fact, $S, S-\mathrm{Me}_{2} \mathrm{Spm}$ downregulated ODC activity 
even better than DFMO. By contrast, the analogs only slightly induced SSAT activity, $S$ - and $S$, $S$-isomers being the most potent ones. All the stereoisomers accumulated in the cells to concentrations near that of the natural polyamines, and decreased the intracellular levels of natural polyamines, especially when used in combination with DFMO. $S$-MeSpd and $S, S-\mathrm{Me}_{2} \mathrm{Spm}$ accumulated in somewhat higher intracellular concentration than the other stereoisomers, and most effectively depleted the natural polyamines. When different analog concentrations $(1,10$ or $100 \mu \mathrm{M})$ were tested, it was found that the higher the analog concentration, the more efficient reduction of the natural polyamines (data not shown). As we reported previously [20], all analogs supported cell growth during DFMO-induced polyamine depletion for 3 days (data not shown). Of $\mathrm{Me}_{2} \mathrm{Spm}$ stereoisomers, only S,S was metabolized to MeSpd (Table 2), and both MeSpd enantiomers were metabolized to $\alpha$-MeSpm by spermine synthase (Table 1). These $\alpha$-MeSpm enantiomers can be then further converted to $\alpha$-MeSpd and Spd by SMO, with $S$-MeSpm being preferred to $R-\mathrm{MeSpm}$ (data not shown).

Table 3 depicts AdoMetDC activity and the levels of $S$-adenosylmethionine (SAM) and decarboxylated $S$-adenosylmethionine (deSAM) in DU145 cells treated with DFMO and the stereoisomers or natural polyamines for 24, 48 and 72 hours. As expected, DFMO caused an induction of the enzyme activity, and led to accumulation of deSAM, and the treatment with natural polyamines or their analogs suppressed the enzyme activity and reduced the amount of deSAM. Based on both activity and nucleoside data, S-MeSpd suppressed the enzyme activity more than $R$-MeSpm and $R, R$ was the best suppressor of AdoMetDC activity among the $\mathrm{Me}_{2} \mathrm{Spm}$ stereoisomers. Table 3 also shows that the methylated analogs were not as efficient AdoMetDC suppressors as their corresponding natural polyamines.

\section{Uptake of the stereoisomers}

The ability of the stereoisomers to compete for uptake with the natural polyamines was investigated in DU145 cells by 10 -min competition assays with $\left[{ }^{14} \mathrm{C}\right]$-labelled spermidine or spermine (Figure 1). In such a short time, the antizyme does not downregulate the polyamine uptake. $S$-MeSpd and $S, S-\mathrm{Me}_{2} \mathrm{Spm}$ were clearly least effective competitors. Similar results were obtained with mouse primary fetal fibroblasts (data not shown). Since we found differences in the ability of the stereoisomers to inhibit ODC activity, we hypothesized that the stereoisomers might differently affect the synthesis of the functional antizyme by inducing ribosomal frameshifting on antizyme mRNA. Therefore, antizyme-dependent uptake of the stereoisomers was studied by blocking antizyme expression by pre-incubating DU145 cells with a translation inhibitor, cycloheximide (CHX). After 1 hour, the analogs were added for further $2 \mathrm{~h}$ and the intracellular concentrations of the analogs were measured with HPLC. As shown in Figure 2, without CHX treatment there were no differences in the accumulation of the distinct stereoisomers of MeSpd or $\mathrm{Me}_{2} \mathrm{Spm}$. By contrast, when CHX was added, $S$ - and $S, S$-isomers accumulated in higher concentrations than the others, suggesting that these stereoisomers more effectively induce antizyme expression.

\section{ODC antizyme frameshifting}

To investigate in more detail whether $S$ - and $S, S$-isomers induce antizyme frameshifting more efficiently than the other isomers, HEK293 cells were transfected with a dual luciferase reporter plasmid containing the antizyme sequences required for polyamine induced frameshifting between the Renilla and firefly luciferase genes [29]. The firefly luciferase ORF lacks an initiation codon and can only be expressed as a fusion protein with Renilla luciferase if translational frameshifting occurs. Frameshifting efficiency was calculated as a ratio of the firefly to Renilla luciferase activities standardized to an in-frame control. Figure 3a indicates that $S$-MeSpd and $S, S-\mathrm{Me}_{2} \mathrm{Spm}$ were more potent than the other stereoisomers at inducing antizyme frameshifting. To rule out the possibility that the better frameshifting efficiency was caused by higher intracellular analog concentrations, frameshifting was also tested in rabbit reticulocyte lysate. As depicted in Figure 3b, differences existed between the stereoisomers, S-MeSpd and S,S$\mathrm{Me}_{2} \mathrm{Spm}$ again being more efficient than the others.

\section{Alternative splicing of SSAT}


Since the stereoisomers differently affected SSAT activity, we next tested whether there were differences between the stereoisomers in their ability to regulate the alternative splicing of SSAT pre-mRNA. Mouse primary foetal fibroblasts were first exposed to the protein synthesis inhibitor CHX in order to block the NMD pathway and rapid degradation of the unproductive splice variant. After 1 hour, polyamine analogs were added, and incubation was continued for 7 hours. Figure 4 shows the amount of the unproductive splice variant (SSAT-X) relative to total SSAT mRNA (SSAT + SSAT-X) as measured by quantitative RT-PCR. The treatment with CHX led to marked accumulation of the unproductive variant due to inhibition of NMD, and $S, S-\mathrm{Me}_{2} \mathrm{Spm}$ and $S$-MeSpd were the most effective isomers in decreasing the generation of the unproductive variant of SSAT.

\section{Translational regulation of AdoMetDC in vitro}

The expression of AdoMetDC is regulated mainly through translation of its $\mathrm{uORF}$, where polyamines suppress the translation of downstream AdoMetDC protein [30]. Since our cell culture data showed differences in the AdoMetDC activity and deSAM level between the stereoisomers, we further investigated whether they differently affected the translation of AdoMetDC uORF. We translated uORFluciferase fusion construct in rabbit reticulocyte lysate with or without added natural polyamines or the analogs. As expected, all polyamines suppressed the translation of the fusion construct (Figure 5). However, marked differences existed between the tested compounds, the natural polyamines being better suppressors than the analogs. In line with our cell culture data we found that $S$-MeSpd and $R, R-\mathrm{Me}_{2} \mathrm{Spm}$ were significantly more efficient suppressors of AdoMetDC uORF translation than the other stereoisomers.

\section{DISCUSSION}

Polyamines participate in several important cellular processes such as cell cycle regulation, differentiation, apoptosis, protein synthesis and modulation of ion channels. Some of those processes require covalent binding of polyamines to proteins, of which a well-known example is the hypusination of eukaryotic translation initiation factor 5A (eIF5A) protein [31]. Other polyamine effects are mediated through their ionic interactions with cellular anionic sites. The difference between polyamines and inorganic cations such as $\mathrm{Mg}^{2+}$ is that the charges are distributed along a conformationally flexible carbon backbone, allowing them to interact with various targets, especially the polynucleotides RNA and DNA. Through these interactions, the polyamines influence the expression of many important genes, among which are the genes involved in their own metabolism.

Our present data revealed significant differences between the different stereoisomers of MeSpd and $\mathrm{Me}_{2} \mathrm{Spm}$ in their ability to regulate several components of polyamine homeostasis, such as uptake and the expression of the rate-limiting biosynthetic and catabolic enzymes, ODC, AdoMetDC and SSAT. Earlier studies have indicated that polyamines and their close structural analogs induce +1 ribosomal frameshifting in ODC antizyme mRNA $[9,11,27,32]$. Our results from uptake and frameshifting studies show that $S$ - and $S, S$-isomers were more effective than the other stereoisomers of MeSpd and $\mathrm{Me}_{2} \mathrm{Spm}$ at inducing antizyme frameshifting, and the results from in vitro frameshifting are in line with the cell culture studies. Furthermore, $S$ - and $S, S$-stereoisomers were the most efficient in downregulating ODC activity. In fact, $S, S-\mathrm{Me}_{2} \mathrm{Spm}$ alone was even more potent in decreasing ODC activity than the inhibitor DFMO.

Since antizyme is known not only to promote ODC degradation but also to inhibit polyamine uptake $[12,13,33]$, we examined the uptake and intracellular accumulation of these analogs. In 10-min uptake experiments, where the analogs apparently did not affect the amount of antizyme, S-MeSpd and S,S$\mathrm{Me}_{2} \mathrm{Spm}$ were found to be the least efficient inhibitors of the uptake of Spd and Spm, respectively. However, unexpectedly, after longer time of culture $S$ - and $S, S$-stereoisomers accumulated at slightly higher intracellular concentrations than $R$ - and $R, R$-isomers. When the concentrations of the added analog as well as its metabolic products were added together (Tables 1 and 2), the differences between the stereoisomers were smaller, but still present. The reason why $S$ - and $S, S$-isomers induced antizyme 
frameshifting, but still accumulated at higher concentration than the other isomers, is not understood. The analogs may divergently modulate some yet unidentified cellular regulatory systems.

The mechanisms of polyamine-mediated regulation of the key enzymes of polyamine metabolism are currently not fully understood. It is possible that polyamines directly interact with specific site(s) of target mRNA(s). This view is supported by the work of Higashi and colleagues, who recently found that spermidine binds to and induces a structural change in a bulged-out region of double-stranded RNA, and that the effect is different than that induced by $\mathrm{Mg}^{2+}$ [34]. However, it has been also suggested that polyamines may modulate frameshifting through interactions with the translational machinery, such as tRNAs or the ribosome, and further detailed mechanistic studies are needed to clarify this point.

The interpretation of our cell culture results is complicated by the fact that the intracellular concentrations of $S-\mathrm{MeSpd}$ and $S, S-\mathrm{Me}_{2} \mathrm{Spm}$ were somewhat higher than those of the other isomers. However, this observation must be interpreted cautiously as the intracellular localization and the level of free analog can not readily be determined. To overcome these technical problems, we used in vitro systems to verify the results from cell culture experiments, which indicated that differences existed between the stereoisomers. Our view that the regulation is due to the stereospecificity is also supported by our recent findings, that the stereoisomers of $\alpha$-methylpolyamines significantly differ in their abilities to condense DNA and protect it from hydrogen peroxide-induced oxidative stress in in vitro systems where no endogenous polyamines are present (Dr. TJ Thomas and Dr. MT Hyvönen, unpublished).

Earlier publications indicate that some polyamine metabolic enzymes are stereospecific for their substrates, such as spermidine synthase [35] and ODC [36]. The use of novel chiral $\alpha$-methylated polyamines led to the discovery of a hidden stereospecificity for polyamine oxidase [19], spermine oxidase and deoxyhypusine synthase [20]. In addition, others have reported that deoxyhypusine hydroxylase [37, 38] and similarly spermine synthase [39] show stereocontrol for unsaturated spermidine analogs.

A vast number of polyamine analogs, of which most are achiral, have been synthesized for studying the physiological roles of polyamines and developing drugs for the treatment of cancer and parasitic diseases. Among these compounds are $\mathrm{N}$-alkylated, $\mathrm{C}$-alkylated, unsaturated, fluorinated and aminooxy analogs [40]. The increasing knowledge about polyamine metabolism and their physiological roles has opened up possibilities to develop potent antimetabolites such as the cytotoxic $N$-alkylated analog $N^{1} N^{11}$ diethylnorspermine (DENSPM), which is currently undergoing trials for the chemotherapy of colon carcinoma. One key issue in the drug development is acceptable host toxicity, since total polyamine depletion is difficult to achieve and also may be highly toxic to host. An important goal is to find differences in polyamine metabolism and cellular targets between the host and parasite, or normal and malignant tissue, which can be used to selectively target the drugs. Functional polyamine mimetics with diverse effects on polyamine metabolism may offer the means to selectively regulate key metabolic pathways. Here we show that the optical isomers of $\alpha$-methylated polyamine analogs are promising examples of this approach, by providing evidence that their metabolism and biological effects can be modulated by relatively minor changes such as the configuration of the chiral center. For example, $S$ MeSpd supports hypusine synthesis in DU145 cells during prolonged polyamine depletion with DFMO whereas R-MeSpd does not [20]. Thus, the combined use of DFMO and R-MeSpd may offer practical means to achieve eIF5A-dependent cytostatic response in vivo. In further analog development studies the size, position and chemical nature of substituents can be altered to achieve additional novel biological or metabolic properties for research and/or therapeutic use.

\section{ACKNOWLEDGEMENTS}

This manuscript is dedicated to the memory of Professor Juhani Jänne. The authors warmly thank Dr. David Morris (USA) for providing AdoMetDC uORF-luciferase fusion constructs, and Mrs Anne Karppinen, Mrs Arja Korhonen and Mrs Tuula Reponen (University of Kuopio, Finland) for skilful technical assistance.

\section{FUNDING}


This work was supported by the Academy of Finland [grant numbers 124185 and 128702] and the Russian Foundation for Basic Research [grant number 08-04-91777].

\section{REFERENCES}

1 Tabor, C. W. and Tabor, H. (1984) Polyamines. Annu. Rev. Biochem. 53, 749-790

2 Metcalf, B. W., Bey, P., Danzin, C., Jung, M. J., Casara, P. and Vevert, J. P. (1978) Catalytic irreversible inhibition of mammalian ornithine decarboxylase (E.C. 4.1.1.17) by substrate and product analogues. J. Am. Chem. Soc. 100, 2551-2553

3 Williams-Ashman, H. G. and Schenone, A. (1972) Methyl glyoxal bis(guanylhydrazone) as a potent inhibitor of mammalian and yeast S-adenosylmethionine decarboxylases. Biochem. Biophys. Res. Commun. 46, 288-295

4 Casara, P., Marchal, P., Wagner, J. and Danzin, C. (1989) 5'-\{[(Z)-4-amino-2butenyl]melthylamino \}-5'-deoxyadenosine: a potent enzyme-activated irreversible inhibitor of Sadenosyl-L-methionione decarboxylase from Escherichia coli. J. Am. Chem. Soc. 111, 9111-9113

5 Wolff, A. C., Armstrong, D. K., Fetting, J. H., Carducci, M. K., Riley, C. D., Bender, J. F., Casero, R. A.,Jr and Davidson, N. E. (2003) A phase II study of the polyamine analog N1,N11diethylnorspermine (DENSpm) daily for five days every 21 days in patients with previously treated metastatic breast cancer. Clin. Cancer Res. 9, 5922-5928

6 Simoneau, A. R., Gerner, E. W., Nagle, R., Ziogas, A., Fujikawa-Brooks, S., Yerushalmi, H., Ahlering, T. E., Lieberman, R., McLaren, C. E., Anton-Culver, H. and Meyskens, F. L.,Jr. (2008) The effect of difluoromethylornithine on decreasing prostate size and polyamines in men: Results of a year-long phase IIb randomized placebo-controlled chemoprevention trial. Cancer Epidemiol. Biomarkers Prev. 17, 292-299

7 Hahm, H. A., Ettinger, D. S., Bowling, K., Hoker, B., Chen, T. L., Zabelina, Y. and Casero, R. A.,Jr. (2002) Phase I study of N(1),N(11)-diethylnorspermine in patients with non-small cell lung cancer. Clin. Cancer Res. 8, 684-690

8 Meyskens, F. L.,Jr and Gerner, E. W. (1999) Development of difluoromethylornithine (DFMO) as a chemoprevention agent. Clin. Cancer Res. 5, 945-951

9 Matsufuji, S., Matsufuji, T., Miyazaki, Y., Murakami, Y., Atkins, J. F., Gesteland, R. F. and Hayashi, S. (1995) Autoregulatory frameshifting in decoding mammalian ornithine decarboxylase antizyme. Cell. 80, 51-60

10 Rom, E. and Kahana, C. (1994) Polyamines regulate the expression of ornithine decarboxylase antizyme in vitro by inducing ribosomal frame-shifting. Proc. Natl. Acad. Sci. U.S.A. 91, 3959-3963

11 Balasundaram, D., Dinman, J. D., Wickner, R. B., Tabor, C. W. and Tabor, H. (1994) Spermidine deficiency increases +1 ribosomal frameshifting efficiency and inhibits Ty1 retrotransposition in saccharomyces cerevisiae. Proc. Natl. Acad. Sci. U.S.A. 91, 172-176

12 Mitchell, J. L., Judd, G. G., Bareyal-Leyser, A. and Ling, S. Y. (1994) Feedback repression of polyamine transport is mediated by antizyme in mammalian tissue-culture cells. Biochem. J. 299, 1922

13 Suzuki, T., He, Y., Kashiwagi, K., Murakami, Y., Hayashi, S. and Igarashi, K. (1994) Antizyme protects against abnormal accumulation and toxicity of polyamines in ornithine decarboxylaseoverproducing cells. Proc. Natl. Acad. Sci. U.S.A. 91, 8930-8934

14 Ruan, H., Shantz, L. M., Pegg, A. E. and Morris, D. R. (1996) The upstream open reading frame of the mRNA encoding S-adenosylmethionine decarboxylase is a polyamine-responsive translational control element. J. Biol. Chem. 271, 29576-29582

15 Hyvönen, M. T., Uimari, A., Keinänen, T. A., Heikkinen, S., Pellinen, R., Wahlfors, T., Korhonen, A., Narvanen, A., Wahlfors, J., Alhonen, L. and Jänne, J. (2006) Polyamine-regulated unproductive splicing and translation of spermidine/spermine N1-acetyltransferase. RNA. 12, 1569-1582 
16 Lakanen, J. R., Coward, J. K. and Pegg, A. E. (1992) Alpha-methyl polyamines: Metabolically stable spermidine and spermine mimics capable of supporting growth in cells depleted of polyamines. J. Med. Chem. 35, 724-734

17 Järvinen, A., Grigorenko, N., Khomutov, A. R., Hyvönen, M. T., Uimari, A., Vepsäläinen, J., Sinervirta, R., Keinänen, T. A., Vujcic, S., Alhonen, L., Porter, C. W. and Jänne, J. (2005) Metabolic stability of alpha-methylated polyamine derivatives and their use as substitutes for the natural polyamines. J. Biol. Chem. 280, 6595-6601

18 Keinänen, T. A., Järvinen, A., Uimari, A., Vepsäläinen, J., Khomutov, A. R., Grigorenko, N. A., Hyvönen, M. T., Cerrada-Gimenez, M., Alhonen, L. and Jänne, J. (2007) Alpha-methylated polyamines as potential drugs and experimental tools in enzymology. Mini Rev. Med. Chem. 7, 813820

19 Järvinen, A. J., Cerrada-Gimenez, M., Grigorenko, N. A., Khomutov, A. R., Vepsäläinen, J. J., Sinervirta, R. M., Keinänen, T. A., Alhonen, L. I. and Jänne, J. E. (2006) Alpha-methyl polyamines: Efficient synthesis and tolerance studies in vivo and in vitro. first evidence for dormant stereospecificity of polyamine oxidase. J. Med. Chem. 49, 399-406

20 Hyvönen, M. T., Keinänen, T. A., Cerrada-Gimenez, M., Sinervirta, R., Grigorenko, N., Khomutov, A. R., Vepsäläinen, J., Alhonen, L. and Jänne, J. (2007) Role of hypusinated eukaryotic translation initiation factor 5A in polyamine depletion-induced cytostasis. J. Biol. Chem. 282, 34700-34706

21 Alhonen, L., Karppinen, A., Uusi-Oukari, M., Vujcic, S., Korhonen, V. P., Halmekytö, M., Kramer, D. L., Hines, R., Jänne, J. and Porter, C. W. (1998) Correlation of polyamine and growth responses to N1,N11-diethylnorspermine in primary fetal fibroblasts derived from transgenic mice overexpressing spermidine/spermine N1-acetyltransferase. J. Biol. Chem. 273, 1964-1969

22 Grigorenko, N., Khomutov, A. R., Keinänen, T. A., Järvinen, A., Alhonen, L., Jänne, J. and Vepsäläinen, J. (2007) Synthesis of novel optical isomers of alpha-methylpolyamines. Tetrahedron. 63, 2257-2262

23 Hyvönen, T., Keinänen, T. A., Khomutov, A. R., Khomutov, R. M. and Eloranta, T. O. (1992) Monitoring of the uptake and metabolism of aminooxy analogues of polyamines in cultured cells by high-performance liquid chromatography. J. Chromatogr. 574, 17-21

24 Giles, K. W. and Myers, A. (1965) An improved diphenylamine method for the estimation of deoxyribonucleic acid. Nature. 206, 93-93

25 Jänne, J. and Williams-Ashman, H. G. (1971) On the purification of L-ornithine decarboxylase from rat prostate and effects of thiol compounds on the enzyme. J. Biol. Chem. 246, 1725-1732

26 Bernacki, R. J., Bergeron, R. J. and Porter, C. W. (1992) Antitumor activity of N,N'bis(ethyl)spermine homologues against human MALME-3 melanoma xenografts. Cancer Res. 52, 2424-2430

27 Petros, L. M., Graminski, G. F., Robinson, S., Burns, M. R., Kisiel, N., Gesteland, R. F., Atkins, J. F., Kramer, D. L., Howard, M. T. and Weeks, R. S. (2006) Polyamine analogs with xylene rings induce antizyme frameshifting, reduce ODC activity, and deplete cellular polyamines. J. Biochem. 140, 657-666

28 Grentzmann, G., Ingram, J. A., Kelly, P. J., Gesteland, R. F. and Atkins, J. F. (1998) A dualluciferase reporter system for studying recoding signals. RNA. 4, 479-486

29 Howard, M. T., Shirts, B. H., Zhou, J., Carlson, C. L., Matsufuji, S., Gesteland, R. F., Weeks, R. S. and Atkins, J. F. (2001) Cell culture analysis of the regulatory frameshift event required for the expression of mammalian antizymes. Genes Cells. 6, 931-941

30 Law, G. L., Raney, A., Heusner, C. and Morris, D. R. (2001) Polyamine regulation of ribosome pausing at the upstream open reading frame of S-adenosylmethionine decarboxylase. J. Biol. Chem. 276, 38036-38043

31 Park, M. H., Cooper, H. L. and Folk, J. E. (1981) Identification of hypusine, an unusual amino acid, in a protein from human lymphocytes and of spermidine as its biosynthetic precursor. Proc. Natl. Acad. Sci. U.S.A. 78, 2869-2873 
32 Mitchell, J. L., Leyser, A., Holtorff, M. S., Bates, J. S., Frydman, B., Valasinas, A. L., Reddy, V. K. and Marton, L. J. (2002) Antizyme induction by polyamine analogues as a factor of cell growth inhibition. Biochem. J. 366, 663-671

33 Sakata, K., Kashiwagi, K. and Igarashi, K. (2000) Properties of a polyamine transporter regulated by antizyme. Biochem. J. 347, 297-303

34 Higashi, K., Terui, Y., Inomata, E., Katagiri, D., Nomura, Y., Someya, T., Nishimura, K.

Kashiwagi, K., Kawai, G. and Igarashi, K. (2008) Selective structural change of bulged-out region of double-stranded RNA containing bulged nucleotides by spermidine. Biochem. Biophys. Res. Commun. 370, 572-577

35 Pankaskie, M. C., Abdel-Monem, M. M., Raina, A., Wang, T. and Foker, J. E. (1981) Inhibitors of polyamine biosynthesis. 9. Effects of S-adenosyl-L-methionine analogues on mammalian aminopropyltransferases in vitro and polyamine biosynthesis in transformed lymphocytes. J. Med. Chem. 24, 549-553

36 Qu, N., Ignatenko, N. A., Yamauchi, P., Stringer, D. E., Levenson, C., Shannon, P., Perrin, S. and Gerner, E. W. (2003) Inhibition of human ornithine decarboxylase activity by enantiomers of difluoromethylornithine. Biochem. J. 375, 465-470

37 Byers, T. L., Ganem, B. and Pegg, A. E. (1992) Cytostasis induced in L1210 murine leukaemia cells by the S-adenosyl-L-methionine decarboxylase inhibitor 5'-([(Z)-4-amino-2-butenyl]methylamino)5'-deoxyadenosine may be due to hypusine depletion. Biochem. J. 287, 717-724

38 Byers, T. L., Wiest, L., Wechter, R. S. and Pegg, A. E. (1993) Effects of chronic 5'-([(Z)-4-amino-2butenyl]methylamino)-5'-deoxy- adenosine (AbeAdo) treatment on polyamine and eIF-5A metabolism in AbeAdo-sensitive and -resistant L1210 murine leukaemia cells. Biochem. J. 290, 115121

39 Pegg, A. E., Nagarajan, S., Naficy, S. and Ganem, B. (1991) Role of unsaturated derivatives of spermidine as substrates for spermine synthase and in supporting growth of SV-3T3 cells. Biochem. J. 274, 167-171

40 Pegg, A. E., Poulin, R. and Coward, J. K. (1995) Use of aminopropyltransferase inhibitors and of non-metabolizable analogs to study polyamine regulation and function. Int. J. Biochem. Cell Biol. 27, 425-442 


\section{FIGURE LEGENDS}

Figure 1 Ability of the (a) MeSpd and (b) $\mathrm{Me}_{2} \mathrm{Spm}$ stereoisomers to compete with the natural polyamines for uptake.

Competition assays were performed by 10 -min incubation of DU145 cells with $10 \mu \mathrm{M}\left[{ }^{14} \mathrm{C}\right]$-labelled (a) Spd or (b) Spm and 1, 10 or $100 \mu \mathrm{M}$ of the competing analogs. Data are normalized to control (without competitor; $100 \%$ ) and expressed as means \pm S.D., $n=3$.

Figure 2 Effect of antizyme on the uptake of the MeSpd and $\mathrm{Me}_{2} \mathrm{Spm}$ stereoisomers.

DU145 cells were incubated with or without cycloheximide (CHX, $10 \mu \mathrm{g} / \mathrm{ml})$ for $1 \mathrm{~h}$, after which the analogs $(100 \mu \mathrm{M})$ were added, and incubation continued for $2 \mathrm{~h}$. No metabolism of the analogs were detected by HPLC in $2 \mathrm{~h}$. Data are means \pm S.D., $n=3$.

Figure 3 Induction of ODC antizyme frameshifting by the stereoisomers of $\mathrm{MeSpd}$ and $\mathrm{Me}_{2} \mathrm{Spm}$. (a) HEK293 cells were pretreated for $48 \mathrm{~h}$ with $2.5 \mathrm{mM}$ DFMO and transfected with dual luciferase reporter plasmid containing antizyme frameshift site. Polyamines and analogs, $2.5 \mathrm{mM}$ DFMO and $1 \mathrm{mM}$ aminoguanidine were added $12 \mathrm{~h}$ after transfection and the cells collected 24 hours later. The analogs were tested at 5 different concentrations; the results from experiments performed with optimal concentrations for frameshifting by MeSpd and $\mathrm{Me}_{2} \mathrm{Spm}$ are shown $(1.25 \mu \mathrm{M}$ and $2.5 \mu \mathrm{M}$, respectively). Data are means \pm S.D., $n=10-13$. (b) Dual luciferase reporter plasmid was translated in rabbit reticulocyte lysate using optimal concentrations of MeSpd $(400 \mu \mathrm{M})$ and $\mathrm{Me}_{2} \operatorname{Spm}(100 \mu \mathrm{M})$. Results are means \pm S.D., $\mathrm{n}=12$ from three independent experiments, statistical analysis was done using Student's t-test.

Figure 4 Effect of the stereoisomers of MeSpd and $\mathrm{Me}_{2} \mathrm{Spm}$ on the alternative splicing of SSAT premRNA.

Primary mouse foetal fibroblasts were treated with protein synthesis inhibitor cycloheximide (CHX, 10 $\mu \mathrm{g} / \mathrm{ml})$ for $8 \mathrm{~h}$, of which the last $7 \mathrm{~h}$ with the stereoisomers $(100 \mu \mathrm{M})$. The relative expression level of SSAT-X to total SSAT mRNA was analyzed by qRT-PCR. Data are means \pm S.D., $n=3$, statistical comparisons are to CHX-treated cells.

Figure 5 Ability of the natural polyamines and the stereoisomers of $\mathrm{MeSpd}$ and $\mathrm{Me}_{2} \mathrm{Spm}$ to suppress AdoMetDC uORF translation in vitro.

A fusion construct containing AdoMetDC uORF and luciferase reporter was translated in rabbit reticulocyte lysate in the absence or presence of added polyamines and analogs (Spd and MeSpd $250 \mu \mathrm{M}$, $\mathrm{Spm}$ and $\left.\mathrm{Me}_{2} \mathrm{Spm} 100 \mu \mathrm{M}\right)$. The expression levels were compared to a control plasmid $(=100 \%)$ where the initiation codon of uORF was mutated to AUA (direct translation of luciferase). Data are expressed as means \pm S.D., $n=6$. 


\section{Table 1 Effect of MeSpd stereoisomers on ODC and SSAT activities and intracellular polyamine pools in DU145 cells after $72 \mathrm{~h}$ treatment}

DU145 cells were treated with $100 \mu \mathrm{M}$ analogs with and without $5 \mathrm{mM}$ DFMO for 72 hours. $\mathrm{N}^{1}$-acetylspermidine and $\mathrm{N}^{1}$-acetylspermine levels were below detection limit. Results are means \pm S.D., $n=3$. n.d., not detectable; rac, racemic.

\begin{tabular}{|c|c|c|c|c|c|c|c|c|}
\hline Treatment & $\begin{array}{c}\text { ODC } \\
(\mathrm{pmol} / \mathrm{h} / \mu \mathrm{g} D \mathrm{DN})\end{array}$ & $\begin{array}{c}\text { SSAT } \\
(p m o l / 10 \mathrm{~min} / \\
\mu \mathrm{g} \mathrm{DNA})\end{array}$ & $\mathrm{Pu}$ & Spd & Spm & MeSpd & $\mathrm{pm}$ & $\begin{array}{l}\mathrm{MeSpd}+ \\
\mathrm{MeSpm}\end{array}$ \\
\hline Control & $14.56 \pm 0.14$ & $11.2 \pm 0.3$ & $123 \pm 4$ & $464 \pm 8$ & $201 \pm 2$ & 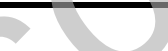 & & \\
\hline Rac & $0.40 \pm 0.06$ & $12.8 \pm 0.3$ & n.d. & $40 \pm 1$ & $167 \pm 15$ & $413 \pm 23$ & $100 \pm 14$ & 513 \\
\hline$R$ & $0.74 \pm 0.05$ & $11.2 \pm 0.4$ & n.d. & $45 \pm 1$ & $177 \pm 5$ & $375 \pm 9$ & $126 \pm 17$ & 501 \\
\hline$S$ & $0.46 \pm 0.03$ & $14.7 \pm 0.4$ & n.d. & $32 \pm 0$ & $154 \pm 3$ & $477 \pm 10$ & $80 \pm 9$ & 557 \\
\hline DFMO & $0.14 \pm 0.01$ & $11.4 \pm 0.0$ & n.d. & $21 \pm 3$ & $195 \pm 10$ & & & \\
\hline $\mathrm{DFMO}+R a c$ & $0.06 \pm 0.01$ & $13.1 \pm 1.3$ & n.d. & $<5$ & $50 \pm 1$ & $599 \pm 10$ & $180 \pm 5$ & 779 \\
\hline $\mathrm{DFMO}+R$ & $0.08 \pm 0.01$ & $17.0 \pm 9.4$ & n.d. & n.d. & $45 \pm 2$ & $554 \pm 18$ & $191 \pm 15$ & 745 \\
\hline $\mathrm{DFMO}+S$ & $0.04 \pm 0.01$ & $22.6 \pm 7.0$ & n.d. & $<5$ & $57 \pm 3$ & $650 \pm 11$ & $112 \pm 9$ & 762 \\
\hline
\end{tabular}


Table 2 Effect of $\mathrm{Me}_{2} \mathrm{Spm}$ stereoisomers on ODC and SSAT activities and intracellular polyamine pools in DU145 cells after $72 \mathrm{~h}$ treatment

DU145 cells were treated with $100 \mu \mathrm{M}$ analogs with and without $5 \mathrm{mM}$ DFMO for 72 hours. $\mathrm{N}^{1}$-acetylspermidine and $\mathrm{N}^{1}$-acetylspermine levels were below detection limit. Results are means \pm S.D., $n=3$. n.d., not detectable; rac, racemic.

\begin{tabular}{|c|c|c|c|c|c|c|c|c|}
\hline Treatment & $\begin{array}{c}\text { ODC } \\
(\mathrm{pmol} / \mathrm{h} / \mu \mathrm{g} \mathrm{DNA})\end{array}$ & $\begin{array}{c}\text { SSAT } \\
(p m o l / 10 \mathrm{~min} / \\
\mu g \mathrm{DNA})\end{array}$ & $\mathrm{Pu}$ & Spd & Spm & $\begin{array}{l}\text { MeSpd } \\
\mathrm{pmol} / \mu \mathrm{g}\end{array}$ & $\mathrm{Me}_{2} \mathrm{Spm}$ & $\mathrm{MeSpd}+\mathrm{Me}_{2} \mathrm{Spm}$ \\
\hline Control & $5.99 \pm 0.46$ & $11.5 \pm 1.5$ & $139 \pm 7$ & $402 \pm 18$ & $251 \pm 20$ & & & \\
\hline Rac & $1.06 \pm 0.12$ & $12.6 \pm 1.7$ & $23 \pm 2$ & $78 \pm 7$ & $65 \pm 3$ & $17 \pm 3$ & $480 \pm 21$ & 497 \\
\hline$R, R$ & $1.58 \pm 0.03$ & $12.4 \pm 0.1$ & $34 \pm 2$ & $99 \pm 7$ & $62 \pm 4$ & n.d. & $474 \pm 29$ & 474 \\
\hline$S, S$ & $0.05 \pm 0.00$ & $24.0 \pm 2.3$ & n.d. & $11 \pm 0$ & $26 \pm 2$ & $74 \pm 6$ & $551 \pm 51$ & 625 \\
\hline$R, S$ & $0.92 \pm 0.09$ & $14.6 \pm 0.7$ & $19 \pm 2$ & $79 \pm 2$ & $55 \pm 3$ & n.d. & $545 \pm 24$ & 545 \\
\hline DFMO & $0.17 \pm 0.04$ & $10.7 \pm 1.0$ & n.d. & $15 \pm 4$ & $205 \pm 7$ & & & \\
\hline $\mathrm{DFMO}+\mathrm{Rac}$ & $0.12 \pm 0.02$ & $14.1 \pm 0.3$ & n.d. & $6 \pm 1$ & $10 \pm 1$ & $15 \pm 2$ & $551 \pm 37$ & 566 \\
\hline $\mathrm{DFMO}+R, R$ & $0.15 \pm 0.01$ & $12.3 \pm 0.0$ & n.d. & $8 \pm 1$ & $10 \pm 1$ & n.d. & $573 \pm 13$ & 573 \\
\hline $\mathrm{DFMO}+S, S$ & $0.03 \pm 0.02$ & $22.2 \pm 2.5$ & n.d. & $<5$ & $12 \pm 0$ & $75 \pm 2$ & $557 \pm 4$ & 632 \\
\hline $\mathrm{DFMO}+R, S$ & $0.14 \pm 0.01$ & $14.6 \pm 0.4$ & n.d. & $<5$ & $10 \pm 1$ & n.d. & $594 \pm 14$ & 594 \\
\hline
\end{tabular}


Table 3 Ability of the natural polyamines and the stereoisomers of MeSpd and $\mathrm{Me}_{2} \mathrm{Spm}$ to suppress AdoMetDC activity and to affect intracellular nucleoside (deSAM, SAM) levels in DU145 cells

DU145 cells were cultured with $5 \mathrm{mM}$ DFMO and $100 \mu \mathrm{M}$ analogs for 24, 48 and $72 \mathrm{~h}$. All plates contained also $1 \mathrm{mM}$ aminoguanidine to prevent the oxidation of Spd and Spm by serum amine oxidases. Data are expressed as means \pm S.D., n=3. n.d., not detectable.

\begin{tabular}{|c|c|c|c|c|c|c|c|c|c|}
\hline \multirow[t]{2}{*}{ Treatment } & \multicolumn{3}{|c|}{$\begin{array}{c}\text { AdoMetDC } \\
\left(\mathrm{pmol} / \mathrm{h} / 10^{6} \text { cells }\right)\end{array}$} & \multicolumn{3}{|c|}{$\begin{array}{c}\text { deSAM } \\
\left(\mathrm{pmol} / 10^{6} \text { cells }\right)\end{array}$} & \multicolumn{3}{|c|}{$\begin{array}{l}\text { SAM } \\
\text { mol } / 10^{6} \text { cells) }\end{array}$} \\
\hline & $24 h$ & $48 \mathrm{~h}$ & $72 h$ & $24 h$ & $48 h$ & $72 h$ & $24 h$ & $48 h$ & $72 h$ \\
\hline Control & $879 \pm 11$ & $518 \pm 39$ & $569 \pm 59$ & n.d. & n.d. & n.d. & $108 \pm 9$ & $157 \pm 12$ & $189 \pm 9$ \\
\hline DFMO & $1589 \pm 165$ & $2149 \pm 114$ & $7244 \pm 44$ & $11.5 \pm 0.4$ & $160.3 \pm 13.7$ & $96.1 \pm 14.9$ & $103 \pm 5$ & $128 \pm 4$ & $128 \pm 16$ \\
\hline $\mathrm{DFMO}+\mathrm{Spd}$ & $1262 \pm 63$ & $843 \pm 27$ & $1600 \pm 35$ & n.d. & $10.2 \pm 0.4$ & n.d. & $145 \pm 12$ & $170 \pm 20$ & $219 \pm 26$ \\
\hline $\mathrm{DFMO}+R-\mathrm{MeSpd}$ & $1818 \pm 52$ & $1103 \pm 36$ & $2163 \pm 82$ & $11.3 \pm 1.0$ & $43.9 \pm 5.3$ & $5.0 \pm 0.9$ & $154 \pm 23$ & $195 \pm 25$ & $299 \pm 32$ \\
\hline $\mathrm{DFMO}+S-\mathrm{MeSpd}$ & $1495 \pm 65$ & $1003 \pm 42$ & $2072 \pm 151$ & n.d. & $28.5 \pm 2.3$ & $2.4 \pm 0.3$ & $168 \pm 34$ & $205 \pm 22$ & $251 \pm 55$ \\
\hline $\mathrm{DFMO}+\mathrm{Spm}$ & $602 \pm 3$ & $346 \pm 17$ & $184 \pm 21$ & n.d. & n.d. & n.d. & $146 \pm 19$ & $168 \pm 20$ & $209 \pm 34$ \\
\hline $\mathrm{DFMO}+R, R-\mathrm{Me}_{2} \mathrm{Spm}$ & $639 \pm 54$ & $336 \pm 25$ & $251 \pm 15$ & n.d. & n.d. & $0.4 \pm 0.2$ & $155 \pm 19$ & $192 \pm 16$ & $232 \pm 15$ \\
\hline $\mathrm{DFMO}+\mathrm{S}, \mathrm{S}-\mathrm{Me}_{2} \mathrm{Spm}$ & $769 \pm 34$ & $468 \pm 40$ & $406 \pm 35$ & & $5.9 \neq 0.2$ & $1.5 \pm 0.1$ & $136 \pm 13$ & $209 \pm 36$ & $227 \pm 14$ \\
\hline $\mathrm{DFMO}+R, S-\mathrm{Me}_{2} \mathrm{Spm}$ & $742 \pm 39$ & $449 \pm 23$ & $394 \pm 61$ & n.d. & $9.1 \pm 0.9$ & $0.7 \pm 0.3$ & $180 \pm 23$ & $254 \pm 4$ & $260 \pm 12$ \\
\hline
\end{tabular}



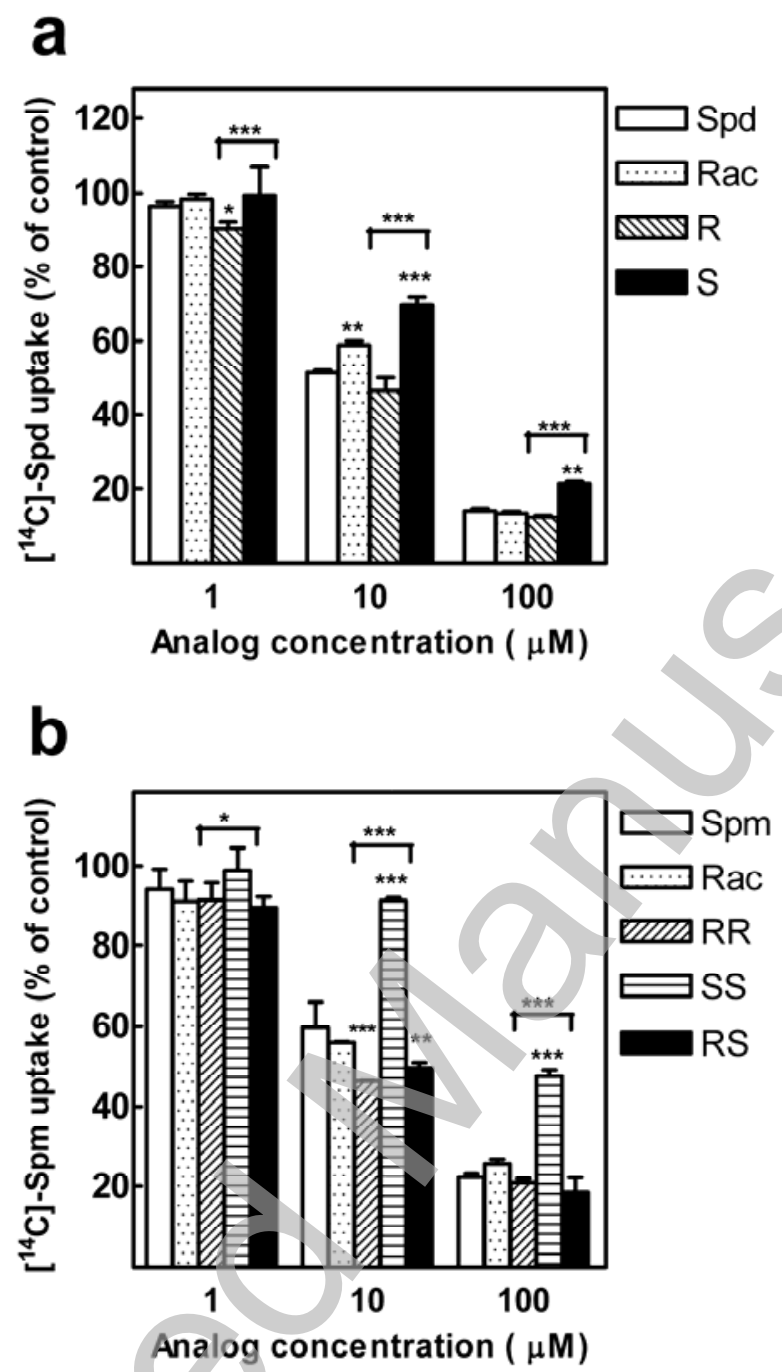

Figure 1. 


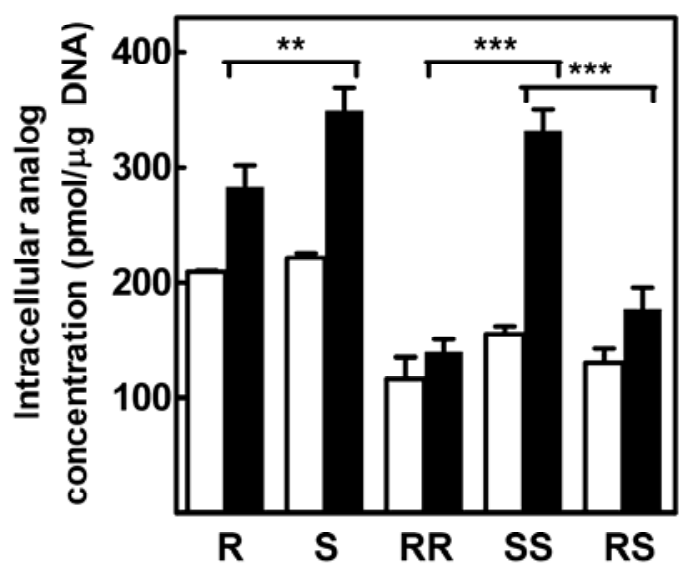

$\square$ without $\mathrm{CHX}$ with $\mathrm{CHX}$

Figure 2. 


\section{a}

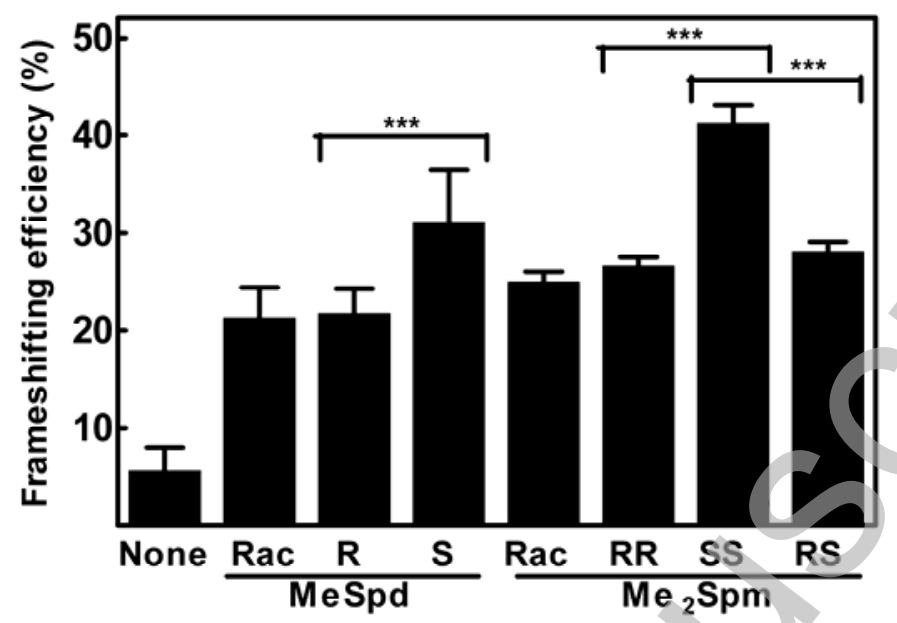

b

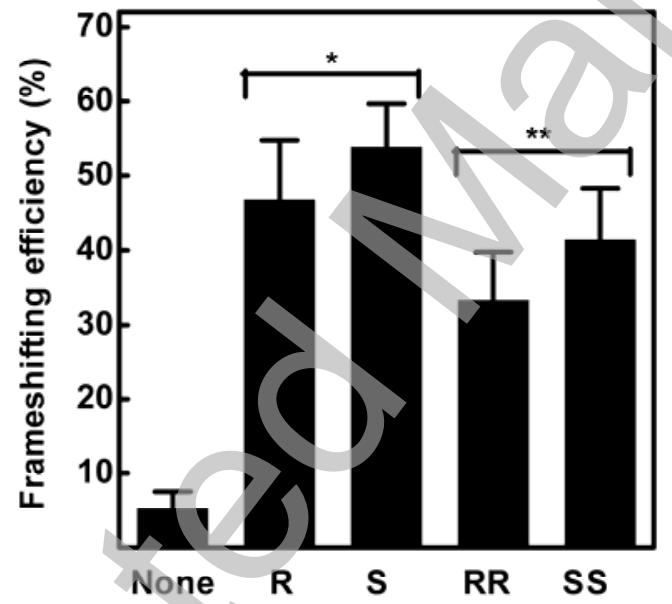

Figure 3 


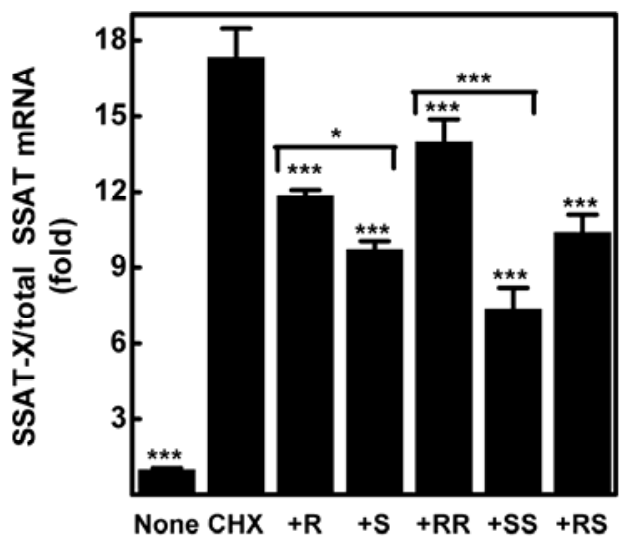

Figure 4 


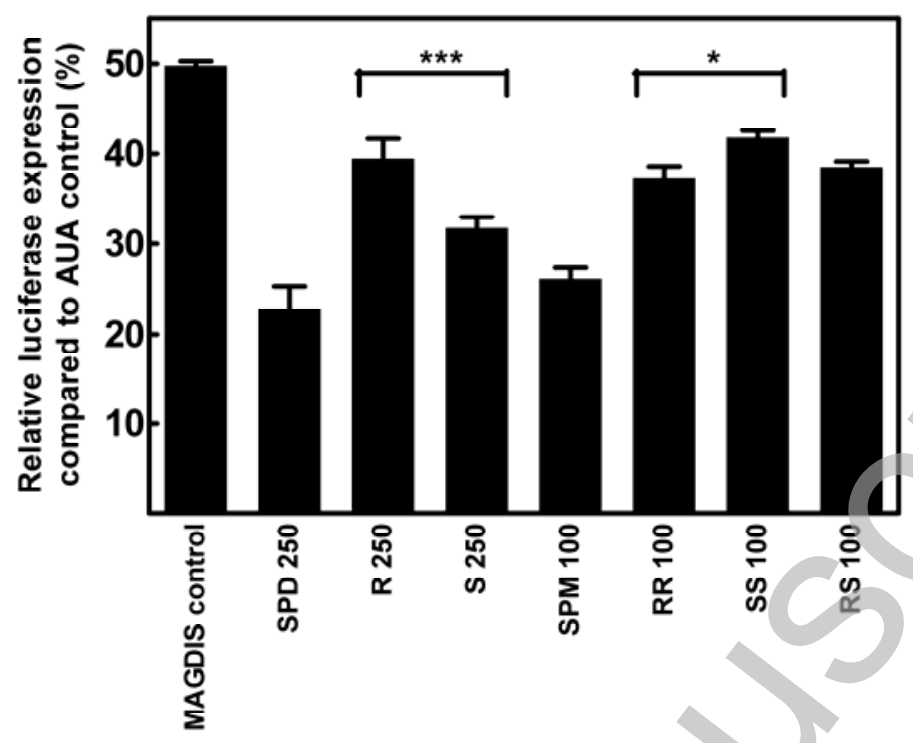

Figure 5 